\title{
PREVALENCE OF DIPTEROUS FLIES ASSOCIATED WITH HUMAN AND ANIMAL DISEASES IN MENOUFIA GOVERNORATE, EGYPT
}

\author{
By \\ AZZA S. ABD EL-HALIM, MOHAMED I. SOLIMAN, NOUR EL-DIN S. ALY \\ AND MICHEAL W. MIKHAIL \\ Research Institute of Medical Entomology, Ministry of Health and Population, \\ Dokki, Giza, Egypt
}

\begin{abstract}
The present study focused on dipterous flies, distribution and their densities in nine centers of Menoufia Governorate, Egypt (Quesna, Shebeen El-Kom, Berkat El-Sabe, El-Bagour, AlShohada, Tala, Menof, Al-Sadat and Ashmon). The result indicated that 30 species belonging to 22 genera and 11 families were trapped from Menoufyia Governorate in spring 2015. Musca domestica, Coproica vegans, Cop. Ferruginata, Sepsis thoracica, S. lateralis and S. fissa were the most abundant species in the Governorate. The results showed that there was no statistically significant according to the total number of flies species between centers $(\mathrm{F}=0.794 \& \mathrm{P}=0.686)$. Data also indicated that there was statistically significant between species according to the total number of flies in Quesna center $(\mathrm{F}=2.576 ; \mathrm{P}=0.040)$, but there was no statistically significant between species according to the total number of flies to other centers, Shebeen El-Kom ( $\mathrm{F}=1.368 ; \mathrm{P}=0.282)$, Berkat El-Sab $(\mathrm{F}=2.00 ; \mathrm{P}=0.95)$, El-Bagour $(\mathrm{F}=0.771 ; \mathrm{P}=0.95)$, Al-Shohada $(\mathrm{F}=0.900 ; \mathrm{P}=0.564)$, Tala $(\mathrm{F}=1.926 ; \mathrm{P}=0.110)$, Menof $(\mathrm{F}=1.640 ; \mathrm{P}=0.170)$, Al-Sadat $(\mathrm{F}=1.537 ; \mathrm{P}=0.216)$, Ashmon $(\mathrm{F}=0.611 ; \mathrm{P}=0.759)$. Shebeen ElKom Center showed the highest prevalence of the species of the most families due to suitable breeding sites. Ashmon showed the lowest prevalence of the most species.
\end{abstract}

Key Words: Egypt, Dipterous flies, densities, Menoufia Governorate.

\section{Introduction}

Dipterous are among the most important insects affecting the health of human and animals (Wilson, 1991). They act as vectors of pathogenic organisms (Smith, 1973). They breed in carrion and decaying organic matters, and attack man body causing myiasis in different sites (Smart, 1965).

This work aimed to survey and to identify dipterous flies of medical and veterinary importance in Menufia Governorate.

\section{Materials and Methods}

This work was done during the spring of the year 2015. Dipterous flies were collected from two villages for each center. Colored flies collections were done by using standard sweeping hand traps from garbage sites, and boxes (El-Bashier et al, 2006), as well as from decayed fruits, vegetables, animals and human excreta. Identification was done by using standard keys (Patton, 1933; James, 1947; Zumpt and Heinz 1950; Kamal, 1958; Zumpt, 1965; Steyskal and El-Baily, 1967; Shaumer and Kamal 1977; 1982; Shaumer et al, 1985; 1989; Morsy et al, 1991; Mohamed and Shoukry, 1991; Amin et al, 1997a).

Data subjected to analysis for variance and of the significant differences, the method of Robert and Sokal (1995) was used.

\section{Results}

The results are shown in tables $(1,2 \& 3)$.

Table 1: Correlation between species according total number of flies in Centers, of Menoufia Governorate.

\begin{tabular}{|l|c|c|c|c|c|c|}
\hline Center & No. & Minimum & Maximum & Mean & STD. & ANOVA test \\
\hline Quesna & 30 & 0.00 & 1245.00 & 69.3000 & 231.60626 & $\mathrm{~F}=2.576, \mathrm{P}=.040$ \\
\hline Shebeen El-Kom & 30 & 0.00 & 1722.00 & 124.7000 & 418.98689 & $\mathrm{~F}=1.368, \mathrm{P}=.282$ \\
\hline Berket El- sab & 30 & 0.00 & 1267.00 & 57.2000 & 230.50460 & $\mathrm{~F}=2.000, \mathrm{P}=.095$ \\
\hline El-Bagour & 30 & 0.00 & 972.00 & 35.1667 & 177.11891 & $\mathrm{~F}=.771, \mathrm{P}=.618$ \\
\hline Al-Shohada & 30 & 0.00 & 535.00 & 23.4333 & 97.55553 & $\mathrm{~F}=.900, \mathrm{P}=.564$ \\
\hline Talla & 30 & 0.00 & 967.00 & 75.6000 & 213.08159 & $\mathrm{~F}=1.926, \mathrm{P}=.110$ \\
\hline Menouf & 30 & 0.00 & 1553.00 & 92.1000 & 328.79659 & $\mathrm{~F}=1.640, \mathrm{P}=.170$ \\
\hline Al-Sadat & 30 & 0.00 & 1319.00 & 47.0000 & 240.61702 & $\mathrm{~F}=1.537 . \mathrm{P}=.216$ \\
\hline Ashmoun & 30 & 0.00 & 1129.00 & 39.3000 & 205.84178 & $\mathrm{~F}=.611, \mathrm{P}=.759$ \\
\hline
\end{tabular}


Table 2: Flies collected from Menoufia Governorate during spring season 2015

\begin{tabular}{|c|c|c|c|c|c|c|c|c|c|}
\hline Species & Quesna & Shebeen El-Kom & Berket-El-Sabe & El- Bagour & El-Shohada & Tala & Menof & El-Sadat & Ashmon \\
\hline Calliphora Vicina R.O. & 2 & 2 & 2 & 1 & 0 & 0 & 1 & 1 & 0 \\
\hline Chrysomyia albiceps (wied.) & 4 & 1 & 2 & 2 & 2 & 3 & 1 & 2 & 0 \\
\hline Lucilia sericata (Meig.) & 8 & 5 & 8 & 3 & 3 & 5 & 3 & 4 & 4 \\
\hline Musca domestica $\mathrm{L}$. & 1245 & 1722 & 1267 & 972 & 535 & 967 & 982 & 1319 & 1129 \\
\hline Musca Sorbans (Wied.) & 3 & 1 & 5 & 0 & 1 & 0 & 1 & 0 & 0 \\
\hline Muscina stabulance (Fallen) & 0 & 1 & 0 & 0 & 1 & 0 & 0 & 1 & 0 \\
\hline Fannia canicularis $($ L.) & 2 & 4 & 0 & 0 & 0 & 9 & 1 & 0 & 0 \\
\hline Stomoxys calcitrans $(\mathrm{L})$. & 0 & 0 & 1 & 4 & 0 & 0 & 0 & 0 & 0 \\
\hline Synthesiomyia nudiseta (Van.) & 0 & 1 & 0 & 0 & 1 & 0 & 0 & 0 & 0 \\
\hline Limnophora variegate $($ Stein) & 0 & 9 & 1 & 0 & 0 & 0 & 1 & 1 & 0 \\
\hline Limnophora multipunctata (S) & 0 & 0 & 0 & 0 & 0 & 0 & 1 & 0 & 0 \\
\hline Physiphora demandata (Fabr.) & 1 & 4 & 1 & 6 & 7 & 2 & 5 & 1 & 3 \\
\hline Piophila casie $(\mathrm{L})$. & 104 & 25 & 5 & 4 & 3 & 0 & 4 & 2 & 5 \\
\hline Parasarcophaga hirtipes Wied. & 0 & 1 & 1 & 0 & 0 & 0 & 1 & 1 & 0 \\
\hline Coproica vagans (Haliday) & 88 & 1601 & 114 & 2 & 14 & 144 & 88 & 0 & 18 \\
\hline Coproica ferruginata (Stenh.) & 10 & 92 & 0 & 0 & 3 & 4 & 1553 & 0 & 1 \\
\hline Coproica digitata (Duda) & 1 & 4 & 1 & 0 & 0 & 0 & 0 & 1 & 0 \\
\hline Ceroptera algira (vill.) & 1 & 1 & 25 & 2 & 1 & 1 & 0 & 0 & 0 \\
\hline Copromyza costalis Zetter & 1 & 21 & 4 & 1 & 25 & 10 & 6 & 0 & 2 \\
\hline Copromyza marginalis (Adams) & 0 & 5 & 0 & 0 & 0 & 0 & 0 & 0 & 0 \\
\hline Limosina brivicostate (Duda) & 1 & 0 & 0 & 0 & 0 & 0 & 0 & 0 & 2 \\
\hline Ischiolepta pusilla (Fallen) & 1 & 0 & 0 & 0 & 0 & 0 & 0 & 0 & 0 \\
\hline Meoneura vagans (Fallen) & 35 & 31 & 26 & 3 & 12 & 6 & 5 & 0 & 4 \\
\hline Hippelate pusio Low & 35 & 64 & 33 & 44 & 10 & 56 & 32 & 74 & 6 \\
\hline Drosophila melanogaster Meig. & 66 & 1 & 1 & 2 & 4 & 4 & 0 & 1 & 0 \\
\hline Drosophila histrioides $\mathrm{O} \& \mathrm{~K}$ & 0 & 3 & 0 & 1 & 2 & 0 & 0 & 1 & 0 \\
\hline Sepsis thoracica (Rob.- Des.) & 339 & 3 & 43 & 1 & 3 & 604 & 67 & 0 & 2 \\
\hline Sepsis lateralis Wied. & 51 & 22 & 110 & 6 & 71 & 50 & 3 & 0 & 3 \\
\hline Sepsis fissa Becker & 81 & 117 & 65 & 1 & 5 & 402 & 8 & 0 & 0 \\
\hline Megaselia scalaris (Loew) & 0 & 0 & 1 & 0 & 0 & 1 & 0 & 1 & 0 \\
\hline
\end{tabular}

Table 3: Correlation between centers according to the total number of flies species in Menoufia Governorate.

\begin{tabular}{|c|c|c|c|c|c|}
\hline No. & Minimum & Maximum & Mean & Std. Deviation & ANOVA test \\
\hline 9 & 703.300 & 3741.000 & 1879.333 & 3741.000 & $\mathrm{~F}=.794, \mathrm{P}=0.686$ \\
\hline
\end{tabular}

\section{Discussion}

This study was carried out in spring 2015 and covered nine centers of Menoufia Governorate in the Nile Delta. The survey yielded specimens belonging to 30 species, 22 genera and 11 families, Calliphoridae, Muscidae, Otitidae, Piophilidae, Sarcophagidae, Sphaeroceridae, Milichiidae, Chloropidae, Drosophilidae, Sepsidae and Phoridae. The results showed that there was no statistically significant according to the total number of flies species between centers $(\mathrm{F}=0.794$ \& $\mathrm{P}=0.686)$. Data also indicated that there was statistically significant between species according to the total number of flies in Quesna Center ( $\mathrm{F}=2.576$ \& $\mathrm{P}=0.040$ ), but without statistically significant between species according to the total number of flies to other centers, Shebeen ElKom ( $\mathrm{F}=1.368 \& \mathrm{P}=0.282)$, Berkat El-Sabe $(\mathrm{F}=2.00 \& \mathrm{P}=0.95)$, El-Bagour $(\mathrm{F}=0.771 \&$ $\mathrm{P}=0.95)$, Al-Shohada $(\mathrm{F}=0.900 \& \mathrm{P}=0.564)$, Tala $(\mathrm{F}=1.926 \& \mathrm{P}=0.110)$, Menof $(\mathrm{F}=1.640$ \& $\mathrm{P}=0.170)$, Al-Sadat $(\mathrm{F}=1.537 \& \mathrm{P}=0.216)$, Ashmon ( $\mathrm{F}=0.611 \& \mathrm{P}=0.759)$. Fam. Mus- cidae: Musca domestica L. was the highest density in all the Governorate Centers.

Limnophora multipuctata (S) was found only in Tala. Musca sorbens Wied., but not found in El-Bagour, Tala, al-Sadat and Ashmon. Stomoxys calcitrans (L.) was not found in Quesna, Shebeen El-Kom, Al-Shohada, Tala, Menof, Al-Sadat and Ashmon. Synthesiomyia nudiseta (Van,) was detected only in Shebeen El-Kom and Al-Shohada. Fam. Calliphoridae: Chrysomyia albiceps (Wied.) showed the highest density in Quesna while Lucilia sericata (Meig.) had the highest density in Berkat El-Sabe and Quesna, but Calliphora vicina (R.O.) was not found in Al-Shohada, Tala and Ashmon. Fam. Otitidae: Physiphora demandata (Fabr.) and Fam. Piophilidae: Piophila casei (L.) was not found in Tala. Fam. Sarcophagidae: Parasarcophaga hirtipes (Wied.) was found in Shebeen El-Kom, Berkat El Sabe, Al Sadat and Menof. Fam. Sphaeroceridae: Coproica vagans (Haliday) was found in all centers, with highest density in Shebeen ElKom, but Coproica ferruginata (Stenh.) not found in El-Bagour, Berket El-Sabe and $\mathrm{Al}$ 
Sadat, with the highest density in Menof. Fam. Milichiidae: Meoneura vagans (Fallen) was not found in Al-Sadat. Fam. Sepsidae: $S$. thoracica (Rob-Des.) and $S$. lateralis Wied. were not found in Al-Sadat with the highest density in Tala and Berkat El-Sabe, while S. fissa Becker showed the highest density in Tala but not found in Al-Sadat and Ashmon. Fam. Phoridae: Megaselia scalaris (Loew) was found in Barkat ElSabe, Al-Sadat and Tala.

Musca domestica and Coproica vagans were the most abundant in all the Governorate Centers. This might be attributed to the accumulation of garbage, decaying fish, human and animals excreta; the highly attractive media for these two flies. The abundance of $M$. domestica all-over the governorate agreed with many Egyptian authors (Taha and Kamal, 1984; Hafez and GamalEldin, 1959; Morsy et al, 1991; Am-in et al, 1998; Gadalla and Abd El-Halim, 2006; Abd El-Halim, 2010; Abd El-Halim et al, 2004; 2005; 2009; Abd El-Halim and Soliman 2011).

Abd El-Halim et al. (2005) studied the abundance and distribution of dipterous flies in five governorates: Qalyoubia, Menoufia, Beheira, Al-Fayium and Assuit, and found that Musca sorbens Wied Parasarcophaga hirtipes Wied, and Physiphora demandata (Fabr.) were the most abundant flies

Piophila casei were found in Menoufia Governorate but neither Stomoxys calcitrans nor $S$. thoracica. The other flies, $M$. domestica, Chrysomyia albiceps, Lucilia sericata and Coproica vagans showed the highest density that agreed with Amin et al, (1998).

On the other hand, Fekry et al. (1997) in Al-Arish reported a family of five persons infested in the eyes (5) and nose (2) with the Oestrus ovis larvae. They concluded that the physicians in the $\mathrm{MOH}$ rural health units should keep in mind opthalmomyiasis when dealing with non-specific catarrhal conjunctivitis particularly those people who are concerned with rearing of farm animals. Mazyad and Soliman (2006) in Cairo studied the biology of the Phorid fly $M$. sacalaris and found that it developed on a synthetic diet at $25^{\circ} \mathrm{C} \& 75 \pm 2 \% \mathrm{RH}$. The mean times for development and survival were for egg incubation $16.3 \mathrm{hr}$ (97.6\%); larval period 7.3 days (97.6\%); pupal period 9.8 days $(95.8 \%$, 91.6\%); adult longevity 29.9 days, 24.8 days. Fecundity was 664.8 eggs. One generation required 19.7 days. They added that the morphological structures were useful for specific to identify the first and second instar larvae collected from human corpses might be used in forensic practice.

Tantawi et al. (2010) in Alexandria reported an accidental involvement of $L$. cuprina in MDT proved to be safe and effective. In November 2008, the laboratory colonies of L. sericata (the species regularly used in MDT) at the Faculty of Science, Alexandria University were renewed by Lucilia flies collected as third instar larvae on exposed rabbit carcasses. Flies from the new colonies were successfully used to heal the diabetic foot wounds of two patients at Alexandria Main University Hospital. Analysis of DNA sequences and adult and larval morphology revealed that these flies were $L$. cuprina. They added that despite the safety of $L$. cuprina strain in MDT, scientists rearing these blow flies for the wound debridement should regularly maintain high quality assurance of their species' identity to avoid possible clinical complications that might result from the introduction of an unexpected and invasive species to their laboratory colonies.

Abosdera and Morsy (2013) in Assuit studied the clinical pictures and pathogenesis of human oral cavity myiasis in ten children and the children's parents. The extracted larvae were Lucilia sericata (four cases), Wohlfahrtia magnifica (three cases), Oestrus ovis (three children and their parents) and Musca d. vicina (one case), which recommended zoonotic myiasis. The predisposing factors were mouth breathing, incompetent lips, low socioeconomic condition, malnutrition, and inability of the child to perform the daily activities due to the neurodegenerative 
disease. Zaglool et al. (2013) in Saudi Arabia reported a case of a 40-year-old male diabetic patient, resident of a rural area, who visited the outpatient clinic of the diabetic center in Alnoor Specialist Hospital. He came to seek medical advice for a single wound in the back of his shoulder one mon th ago. After examination, a larva was eliminated and confirmed as the third-stage larva of Sarcophaga species.

Huchet et al. (2013) reported the first archaeological case of dog ectoparasitosis in the Ancient Egyptian. The study of a mummified young dog dated to the Roman period suggested a significant infestation by dog tick Rhipicephalus sanguineus Latreille, 1806, and louse fly Hippobosca longipennis Fabricius, 1805 as well as puparia of sarcosaprophagous species flies a potential source of myiasis.

Hassan et al. (2014) in Cairo used Lucilia cuprina maggots for treatment of an artificial diabetic foot wound in rabbit. The results showed that the treatment of the diabetic foot was achieved after 13 days. After this period the wound was completely healed and become free of microbial contamination. Morsy (2014) reported that almost non-blood suckers might attack man and animal to deposit their eggs or larvae of myiasis producing flies in skin, nose, eye, lung, ear, anus, vagina, and oral cavity as well as accidental gastrointestinal ones causing pathogenic condition known as myiasis. $\mathrm{He}$ added that nosocomial myiasis must be noted carefully, especially among the hospitalized patients and that nosocomial myiasis illustrated an unusual problem that might confront those responsible for the infection control programs. Also, Abdel-Hafeez et al. (2015) in Minia City reported three cases of wound myiasis among 280 patients with wounds at different parts of bodies. Two of them were diabetic patients. The third one had a history of hypertension with right side hemiplegia 2 years ago. All of them were elder. The larvae removed from cases $1 \& 3$ were the third-stage larvae of Sarcophaga haemorrhoidalis and hat from case 2 were the third-stage larvae of Phormia regina, which was very rare worldwide. They concluded that addition to the open and obsolete wound; diabetes mellitus and low socio-economic circumstances were important predisposing risk factors that led to the occurrence of myiasis in these patients.

El-Tawdy et al. (2016a) in Cairo reported that diabetic foot ulcer (DFU) was and still the major global and devastating complication of diabetes mellitus that affects at least $20 \%$ of diabetic patients during their lifetime and overviewed of the research evidence on maggot debridement therapy as the guide lines to the health professionals who might be users of this form of treatment now and in the future. They concluded that maggot debridement therapy proved to sample and safe worldwide a for diabetic foot ulcer to save money and avoid surgical intervention.

Moreover, El-Tawdy et al. (2016b) stated that osteomyelitis occurred either as a result of hematogenous seeding, contiguous spread of infection to bone from adjacent soft tissues and joints, or direct inoculation of infection into the bone as a result of trauma or surgery They added that hematogenous osteomyelitis was usually monomicrobial, while osteomyelitis due to contiguous spread or direct inoculation is usually polymicrobial. Staphylococcus aureus, coagulase-negative staphylococci and aerobic gram-negative bacilli were the commonest organisms; other pathogens including the streptococci, enterococci, anaerobes, fungi and mycobacteria were implicated. They added that the acute osteomyelitis typically presents with gradual onset of pain over several days. Treatment of osteomyelitis often requires both surgical debridement of necrotic material and antimicrobial therapy for eradication of infection. They concluded that optimal duration of antibiotic therapy is not certain; but continuing the parenteral antimicrobial therapy at least six weeks from the last debridement and recommended the application maggot therapy as an effective and environmentally 
friendly treatment of the complicated necrotic wounds resistant to the conventional treatment and should also be considered in earlier stages of treatment.

\section{Conclusion}

The outcome data of this study in the different centers of Menoufia Governorate pave the way for a better understanding of the dipterous flies as mechanical transmitters of some zoonotic diseases. Consequently, based on these data and others a feasible control measure can be proposed.

Nevertheless, some of the myiasis producing dipterous species especially those of the genus Lucilia proved to have medical application of the human wounds superimposed by pathogenic microorganisms.

\section{References}

Abdel-Hafeez, EH, Mohamed, RM, Belal, US, Atiya, AM, Takamoto, M, Aosai, F, 2015: $\mathrm{Hu}-$ man wound myiasis caused by Phormia regina and Sarcophaga haemorrhoidalis in Minia Governorate, Egypt. Parasitol. Res. 114, 10: 3703-9 Abd El-Halim, AS, 2010: A survey on dipterous flies and their densities in Alexandria and Hurgada, Egypt. J, Egypt. Soc. Parasitol. 40, 1: 27-34.

Abd El-Halim, AS, Gadalla, SM, EI Hamouly, H, 2004: Prevalence of Dipterous flies associated with human and animal diseases in AlObour and $6^{\text {th }}$ October wholesale markets, Egypt. J, Egypt. Soc. Parasitol. 34, 2:459-70.

Abd El-Halim, AS, Soliman, MI, 2011: Dipterous flies species and their densities in Giza and Damietta Egypt. Egypt. Med. J. Teach. Hosp. Inst. 24, 3:267-70.

Abd El-Halim, AS, Soliman, MI, Mikhail, M W, 2009: Prevalence of dipterous flies associated with human and animal diseases in Matruh and South Sinai Governorates, Egypt. J. Egypt. Soc. Parasitol. 39, 3:803-9.

Abd El-Halim, AS, Mostafa, AA, Kalilia, AM 2005: Dipterous fly's species and their densities in fourteen Egyptian Governorates, Egypt. J. Egypt. Soc. Parasitol. 35, 1:351-62.

Abosdera, MM, Morsy, TA, 2013: Oral cavity myiasis in children: First demonstration in Egypt with general review. J. Egypt. Soc. Parasitol. 43, 3:737-46.

Amin AR, Morsy, TA, Shoukry A, Mazyad, S
A, 1997a: Oestrid head maggots in slaughtered sheep in Cairo abattoir, Egypt. J. Egypt. Soc. Parasitol. 27, 3:855-61.

Amin AR, Shoukry A, Morsy, TA, Mazyad, S A, 1997b: Studies of wound myiasis among sheep and goats in North Sinai, Egypt. J. Egypt. Soc. Parasitol. 27, 3:719-37.

Amin, AR, Morsy, TA, Shoukry A, Mazyad, S A, 1998: Studies on myiasis producing flies collected by bait traps at Al-Marg (Qalyubia Governorate). Egypt. J. Egypt. Soc. Parasitol. 28, 1: 45-51.

El-Bashier, ZM, Etewa, S, Morsy, TA, Mohammed, KH, 2006: A preliminary pilot survey (Culex pipiens) Sharkia Governorate. J. Egypt. Soc. Parasitol. 36, 1:81-92.

El-Tawdy, AHF, Ibrahim, EA, Abdallah, ES, Al Sakhawy, EMA, Morsy, TA, 2016a: Maggot debridement therapy (MDT): It is safe and economic for treating a diabetic foot ulcer. J. Egypt. Soc. Parasitol. 46, 1:223- 34

El-Tawdy, AHF, Ibrahim, EA, Morsy, TA, 2016b: An overview of osteomyelitis with reference to treatment in particular maggot debridement therapy (MDT). J. Egypt. Soc. Parasitol. 46, 3:613-24

Fekry, AA, el Serougi, AO, Ayoub, SA, 1997: Oestrus ovis (sheep nasal fly) infesting the eyes and the nose of a camel keeper family. J. Egypt. Soc. Parasitol. 27, 2:493-6.

Gadalla, SM, Abd El-Halim, AS, 2006: Review of black scavenger flies (Sepsidae, Diptera) form Egypt. Ger. Soc. Zool. 50:1-29.

Hafez, M, Gamal-Eldin, FM, 1959: Ecological studies on Stomoxys calcitrans (L.) and Stomoxys sities Rondani in Egypt, with gestations on their control (Diptera: Muscidae). Bull. Soc. Ent. d'Egypte, 53:79-82.

Hassan, MI, Hammad, KM, Fouda, MA, Kamel, MR, 2014: The using of Lucilia cuprina maggots in the treatment of diabetic foot wounds J. Egypt. Soc. Parasitol. 44, 1:125-9

Huchet, JB, Callou, C, Lichtenberg, R, Dunand, F, 2013: The dog mummy, the ticks and the louse fly: Archaeological report of severe ectoparasitosis in Ancient Egypt. Int. J. Paleopathol. 3, 3:165-75.

James, MT, 1947: The Flies that Cause Myiasis in Man. USA Department of Agriculture, Miscellaneous Publication No. 631, Washington, USA Kamal, SA, 1958: Comparative study of 13 species of Calliphoridae and Sarcophagidae (Diptera). 1- Bionomics. Ann. Entom. Soc. Am. 51: 
261-71.

Mazyad, SA, Soliman, M, 2006: Biological and ecological studies on the myiasis producing larvae of Megaselia scalaris with special morphology by scanning electron microscopy. J. Egypt. Soc. Parasitol. 36, 2:585-97.

Mohamed, SK, Shoukry, IF, 1991: The Egyptian species of Sphaeroceridae (Suborder, Cyclorrhapha-Diptera). Ain Shams Sci. Bull. 28, B: 185-200.

Morsy, TA, 2014: Zoonotic myiasis in Egypt: with reference to nosocomial or hospital-acquired myiasis. J. Egypt. Soc. Parasitol. 44, 3: 639-52.

Morsy, TA, Fayad, ME, Salama, MMI, Sabry, AA, El- Serougi, AOM, et al, 1991: Some myiasis producers in Cairo and Giza abattoirs. J. Egypt. Soc. Parasitol. 21, 2:539-46.

Patton, WS, 1933: Studies on the higher Diptera of medical and veterinary importance. A revision of species of the genus Musca based on a comparative study of the male terminalia. Ann. Trop. Med. Parasit. 27:327-30.

Robert, R, Sokal, FJR, 1995: The Principles and Practices of Statistics in Biological Research $3^{\text {rd }}$ Edition. Biometry, Freeman and Company. New York.

Shaumar, N, Kamal, S, 1977: Keys for identification of species of family Syrphida (Diptera) in Egypt. Bull. Soc. Linn. Lyon 46:373-80.

Shaumar, N, Kamal, S, 1982: Keys for identify of species of family Sacophagidae (Diptera) in Egypt. Bull Soc. Ent. D'Egypt 64:121-35.

Shaumar, NF, Mohamed SK, Shoukry, IFI, 1985: Flies of subfamily Muscinae (Muscidae: Diptera) in Egypt. J. Egypt. Soc. Parasitol. 15, 2: 513-23.

Shaumar, NF, Mohamed SK, Mohamed, SA, 1989: Keys for identification of species of family Calliphoridae (Diptera) in Egypt. J. Egypt. Soc. Parasitol. 19, 2:669-81.
Smart, JMA, 1965: A handbook for the Identification of Insects of Medical Importance. $4^{\text {th }}$ Edition, London, British Museum (Natural History), England.

Smith, KGV, 1973: Rodents: Insect and other Arthropods of Medical Importance. Trustees of british Museum, Natural History, London.

Steyskal, GC, El-Bialy, S, 1967: A list of Egyptian Diptera with a bibliography and key to families. Tech. Bull. Ministry of Agriculture 3:3444.

Taha, MA, Kamal, S, 1984: Survey of the insect fauna in certain areas of Southern Sinai. J. Fac. Educ., Ain Shams University 7: 287-300.

Tantawi, TI, Williams, KA, Villet, MH, 2010: An accidental but safe and effective use of Lucilia cuprina (Diptera: Calliphoridae) in maggot debridement therapy in Alexandria, Egypt. J. Med. Entomol. 47, 3:4914.

Wilson, ME, 1991: A World Guide to Infection: Diseases, Distribution, Diagnosis. Oxford, University Press.

Zumpt, F, 1965: Myiasis in Man and Animals in the Old World: A Textbook for Physicians, Veterinarians and Zoologists. Butterworth \& Co., London.

Zumpt, F, Heinz, HJ, 1950: A contribution of the study of the morphology and homology of the male terminalia of Calliphora and Sarcophaga (Diptera: Calliphordae). Ent. Month. Mag. 86:207-17.

Zaglool, DA, Tayeb, K, Khodari, YA, Farooq, MU, 2013: First case report of human myiasis with Sarcophaga species in Makkah city in the wound of a diabetic patient. J. Nat. Sci. Biol. Med. 4, 1:225-8. 